\title{
DETERMINAÇÃO DO COEFICIENTE CONVECTIVO DE TRANSFERÊNCIA DE MASSA DE SEMENTES DE ABÓBORA
}

\author{
G. JOHANN ${ }^{1 *}$, N. C. PEREIRA ${ }^{1}$, E. A. SILVA ${ }^{2}$ \\ ${ }^{1}$ Universidade Estadual de Maringá, Departamento de Engenharia Química \\ ${ }^{2}$ Universidade Estadual do Oeste do Paraná, Centro de Engenharias e Ciências Exatas \\ e-mail: grajohann@yahoo.com.br
}

\begin{abstract}
RESUMO
O processo de secagem convectiva de sementes de abóbora foi estudado, por meio de um modelo fenomenológico de parâmetros concentrados, constituído de duas equações diferenciais ordinárias. O coeficiente de transferência convectiva de massa foi avaliado como sendo uma função linear da umidade das sementes, e os coeficientes lineares, por sua vez, são função logarítmica da temperatura do ar de secagem. Ambos os parâmetros que compuseram a equação linear, empregada para cálculo do coeficiente de transferência de massa, foram reduzidos com o incremento de temperatura do ar de secagem. Os resultados estatísticos indicaram que o modelo descreveu mais de $99 \%$ dos dados experimentais da literatura, apresentando um o erro médio global entre os teores de umidade experimentais e calculados igual a 6,23\%. Dessa forma, as considerações iniciais, o modelo proposto, o ajuste linear do coeficiente convectivo de transferência de massa, e o método numérico empregados no estudo da secagem convectiva de sementes de abóbora foram adequados, resultando em conformidade com os dados experimentais, nas mesmas condições modeladas e simuladas no presente estudo.
\end{abstract}

\section{INTRODUÇÃO}

Com a finalidade de enriquecer a dieta habitual e no intuito de diminuir perdas de alimentos, partes não convencionais de frutas e hortaliças, como sementes e casca, têm sido introduzidas como ingredientes em algumas formulações (DIÓGENES et al. 2013). Sementes de abóbora integram a composição do complemento alimentar conhecido por "multimistura", utilizado em programas assistenciais brasileiros e elaborado com a mistura de diversos ingredientes considerados subprodutos, que contêm características nutritivas similares às de tradicionais farelos de cereais (BELMIRO et al. 2010).

A abóbora é um vegetal originário das Américas do Norte e Central e atualmente é cultivada em todo o mundo, com significativa participação na alimentação de muitos países devido às suas características nutricionais e à coloração atrativa (CARAMEZ et al 2008). De acordo com Sacilik (2007), as sementes de abóbora apresentam valor nutricional considerável para o consumo humano, devido à composição (37,8-45,4\% de lipídeos e 25.2$37,0 \%$ de proteínas), podendo ser ingeridas como petisco, óleo ou farinha, apresentando bons resultados na cura da próstata (ESUOSO et al. 1998).

A semente de abóbora apresenta elevado teor de fibra alimentar $(15,33 \%)$, efeito vermífugo e antioxidante (SANT'ANNA et al. 2006; ESUOSO et al. 1998), porém, conforme Del-Vechio et al. (2005), o consumo in natura de sementes de abóbora pode afetar a biodisponibilidade de determinados nutrientes. 
De acordo com Coelho, Andrade e Finch (1979), o objetivo do armazenamento de grãos é manter as características destes durante um determinado período após a colheita e secagem. Assim, as condições do armazenamento devem manter $\mathrm{o}$ poder germinativo no caso de grãos destinados à semente, as qualidades para a indústria se os grãos são destinados à produção de farinhas ou outro processo tecnológico, e o valor nutritivo se os grãos se destinam à alimentação animal e humana. Ainda, conforme Dalpasquale, Sperandio e Silva (2012), a produção, preservação e comercialização de grãos vêm recebendo atenção acadêmica devido ao potencial em fornecer alimentos em qualidade e quantidade. Segundo Çakmak e Yıldız (2009), há uma série de métodos aplicados para a conservação de produtos agrícolas, que aumentam a vida útil e econômica dos mesmos, fornecendo quantidade os alimentares, estes métodos são: a pasteurização, arrefecimento, manutenção de atmosfera modificada, aplicações químicas, raios gama e beta, além da secagem.

Os objetivos do presente trabalho são modelar a secagem convectiva de sementes de abóbora; validar o modelo, método de discretização e de resolução das equações diferenciais parciais; e determinar o coeficiente convectivo de transferência de massa das sementes de abóbora, como uma função da umidade das sementes e da temperatura do ar de secagem.

\section{MATERIAIS E MÉTODOS}

$\mathrm{O}$ processo de secagem de um material deve-se à transferência simultânea de calor e de massa. Ou seja, a umidade é retirada do sólido pelo fornecimento de calor a este por meio de um meio secante, normalmente um gás, que apresenta menor concentração de umidade em relação à concentração de equilíbrio. De acordo com Esmaiili et al. (2007), os coeficiente de transferência de calor e massa nos processos de secagem dependem das propriedades termofisícas do ar e do material a ser seco, além das características do secador e propriedades do ar de secagem.

No que envolve o processamento desses produtos, o conhecimento a respeito das propriedades físicas dos grãos e sementes são de relevante importância na otimização de processos, na regulagem, construção e operação de equipamentos, e no desenvolvimento de novos projetos envolvendo o processamento de produtos agrícolas (Borém, 2008).

Para a determinação do coeficiente convectivo de transferência de massa de sementes de abóbora, primeiramente foi modelado o processo de secagem convectiva, com base nos experimentos, conduzidos a 50, 60 e $80^{\circ} \mathrm{C}$ e $1 \mathrm{~m} \mathrm{~s}^{-1}$, de Diógenes et al. (2013), que estudaram a secagem de sementes de abóbora em camada fina.

A relação entre a atividade da água, $\mathrm{a}_{\mathrm{W}}$, e a umidade de equilíbrio das sementes de abóbora, $\mathrm{X}_{\mathrm{E}}$, foi estimada pela isoterma de dessorção de Copace (CORRÊA, MARTINS e MELO, 1995), conforme determinado por Teixeira, Andrade e Figueira (2014), sendo:

$\mathrm{X}_{\mathrm{E}}=\mathrm{e}^{-3,396-0,0048 \mathrm{~T}_{\mathrm{S}}+3,1693 \mathrm{a}_{\mathrm{w}}}$

Em que $\mathrm{T}_{\mathrm{S}}$ é a temperatura das sementes de abóbora $\left({ }^{\circ} \mathrm{C}\right)$.

$\mathrm{Na}$ construção do modelo, foi considerado que as sementes de abóbora formam um leito fino; as perdas de calor pelas paredes do secador são desprezíveis; a umidade e temperatura iniciais das sementes são uniformes; transporte unidimensional de calor e massa no leito; distribuições uniformes de temperatura, umidade e velocidade do ar na entrada do secador; na transferência de calor entre $o$ ar de secagem e as sementes, predomina o fenômeno da convecção; o ar de secagem comporta-se gás ideal, nas condições de modelagem; a difusão da umidade ocorre nos micro poros; as variações de temperatura e umidade no ar de secagem são desprezíveis. 
Com base nessas considerações, foram realizados balanços de massa e energia no leito de sementes, resultando em um conjunto de duas equações diferenciais ordinárias:

$\frac{\partial \mathrm{X}}{\partial \mathrm{t}}=\frac{\mathrm{k}_{\mathrm{F}}\left(\mathrm{Y}-\mathrm{Y}^{*}\right)}{(1-\varepsilon) \rho_{\mathrm{S}}}$

$\frac{\partial \mathrm{H}_{\mathrm{S}} \rho_{\mathrm{S}}}{\partial \mathrm{t}}=\mathrm{h}_{\mathrm{c}}\left(\mathrm{T}_{\mathrm{G}}-\mathrm{T}_{\mathrm{S}}\right)-\lambda \frac{\partial \mathrm{X}}{\partial \mathrm{t}}$

Em que $\mathrm{X}$ é a umidade das sementes em base seca (b.s.), t é o tempo (min), $\mathrm{k}_{\mathrm{F}}$ é o coeficiente convectivo de transferência de massa $\left(\mathrm{kg} \mathrm{m}^{-2} \min ^{-1}\right), \mathrm{Y}^{*}$ é a umidade de equilíbrio do ar de secagem (b.s.), Y é a umidade do ar de secagem (b.s.), $\varepsilon$ é a porosidade do leito (-), $\rho_{\mathrm{S}}$ é a densidade das sementes $\left(\mathrm{kg} \mathrm{m}^{-3}\right), \mathrm{H}_{\mathrm{S}}$ é a entalpia das sementes $\left(\mathrm{kJ} \mathrm{kg}^{-1}\right), \mathrm{h}_{\mathrm{c}}$ é o coeficiente volumétrico de transferência de calor $\left(\mathrm{W} \mathrm{m}{ }^{-3}{ }^{\circ} \mathrm{C}^{-1}\right), \mathrm{T}_{\mathrm{G}}$ é a temperatura do ar de secagem $\left({ }^{\circ} \mathrm{C}\right)$, e $\lambda$ é o calor de vaporização da água pura $\left(\mathrm{kJ} \mathrm{kg}^{-1}\right)$.

As condições iniciais foram:

$\mathrm{t}=0, \mathrm{X}=\mathrm{X}_{0}$

$\mathrm{t}=0, \mathrm{~T}_{\mathrm{S}}=\mathrm{T}_{\mathrm{S}_{0}}$

Em que $\mathrm{X}_{0}$ é a umidade inicial das sementes (b.s.), e $\mathrm{T}_{\mathrm{S}_{0}}$ é a temperatura inicial das sementes $\left({ }^{\circ} \mathrm{C}\right)$.

A Tabela 1 apresenta as propriedades termo físicas necessárias para a resolução das Equações 2 e 3.

Tabela 1 - Propriedades termo físicas das sementes de abóbora e do ar de secagem.

\begin{tabular}{ll}
\hline Propriedade & Valor \\
\hline$\rho_{\mathrm{S}}{ }^{1}$ & $647,232 \mathrm{~kg} \mathrm{~m}^{3}$ \\
$\Phi^{1}$ & $0,6324(-)$ \\
$\mathrm{cp}_{\mathrm{S}}{ }^{2}$ & $0,0337 \mathrm{X}(\mathrm{t})+2,3279 \mathrm{~J} \mathrm{~kg}^{-1}{ }^{\circ} \mathrm{C}^{-1}$ \\
$\lambda^{3}$ & $2,162 \times 10^{6}+2 \mathrm{~T}_{\mathrm{S}}$ \\
\hline
\end{tabular}

Fonte: ${ }^{1}$ Andrade et al. (2014), ${ }^{2}$ Kocabiyik, Kayisoglu e Tezer (2009), ${ }^{3}$ Treybal (1980).

Em que $\mathrm{cp}_{\mathrm{S}}$ é o calor específico das sementes de abóbora $\left(\mathrm{J} \mathrm{kg}^{-1}{ }^{\circ} \mathrm{C}^{-1}\right)$, $\Phi$ é a esfericidade média das sementes (-).

A porosidade do leito de sementes de abóbora, $\varepsilon$, foi aproximada à porosidade média do leito de sementes de erva-doce, (SINGH, VISHAL e VISHWAKARMA, 2015), 0,6456 (-), que apresenta esfericidade próxima à das sementes de abóbora.

Considerar o coeficiente de transferência de massa, $\mathrm{k}_{\mathrm{F}}$, como uma constante, geralmente caracteriza uma simplificação para facilitar a solução do modelo. Desse modo, o coeficiente convectivo de transferência de massa foi avaliado neste trabalho como uma função da umidade das sementes e temperatura do ar de secagem, que por sua vez, são funções do tempo. Para tal, uma dependência linear do tipo $\mathrm{k}_{\mathrm{F}}=\mathrm{f}\left(\mathrm{X}, \mathrm{T}_{\mathrm{G}}\right)$, foi estabelecida, conforme Mancini, Massarani e Biscaia Jr (1993):

$\mathrm{k}_{\mathrm{F}}=\beta \mathrm{X}(\mathrm{t})-\alpha$

Em que $\alpha$ e $\beta$ são parâmetros ajustáveis e funções da temperatura do ar de secagem.

Para a resolução do sistema formado pelas Equações 2 e 3, foi empregado o software Maple (versão 13), aplicando-se o método numérico de Rosenbrook, por meio do comando dsolve. Por sua vez, os parâmetros $\alpha$ e $\beta$, foram estimados pelo método simplex, usando o comando NLPSolve, pela minimização do erro quadrático dos desvios da umidade do leito. A relação a ser minimizada foi:

$\mathrm{FOB}=\sum_{\mathrm{i}=1}^{\mathrm{nexp}}\left(\overline{\mathrm{X}_{\mathrm{EXP}}}-\overline{\mathrm{X}_{\mathrm{CAL}}}\right)^{2}$

Em que FOB é a função objetivo, nexp é o número de dados experimentais, $\overline{\mathrm{X}_{\mathrm{EXP}}}$ é a umidade média experimental do leito (b.s.) e $\overline{\mathrm{X}_{\mathrm{CAL}}}$ é a umidade média do leito, calculada pelo modelo (b.s.).

Os resultados foram avaliados com base na análise de erros, ou seja, desvio entre os teores de umidade experimentais e calculados pelo modelo, conforme:

$\overline{\mathrm{E}}=\sum_{\mathrm{i}=1}^{\mathrm{n}_{\exp }} \frac{\mathrm{X}_{\mathrm{EXP}}-\mathrm{X}_{\mathrm{CAL}}}{\mathrm{n}_{\exp }} \times 100 \%$

Em que $\overline{\mathrm{E}}$ é o erro médio (\%), e $\mathrm{n}_{\text {exp }}$ é o número de pontos experimentais. 
Foram, ainda, calculados os valores dos coeficientes de determinação, $\mathrm{R}^{2}$, e do Critério de Seleção de Akaike, AIC, que pode ser entendido como um critério que dá uma pontuação para o modelo, baseado em sua adequação aos dados e na ordem do modelo (Akaike, 1973), é definido como:

$\mathrm{AIC}=\mathrm{n}_{\mathrm{exp}} \cdot \ln (\mathrm{SQ} / \mathrm{N})+2 \mathrm{~K}$

Em que SQ é a soma de quadrados dos desvios, e $\mathrm{K}$ é o número de parâmetros do modelo a ser analisado.

O Critério de Informação de Akaike, é uma medida da qualidade do ajuste do modelo estimado, fornecendo uma medida relativa da perda de informações quando um determinado modelo é usado para descrever dados experimentais, assim, o objetivo é minimizar essa perda.

\section{RESULTADOS E DISCUSSÃO}

A resolução das Equações 2 e 3 ocorreu simultaneamente com a estimação dos parâmetros. Os valores calculados para os coeficientes da Equação $6, \alpha$ e $\beta$, são apresentados na Tabela 2.

Tabela 2 - Parâmetros ajustados da Equação 6.

\begin{tabular}{ccc}
\hline Temperatura $\left({ }^{\circ} \mathrm{C}\right)$ & $\alpha$ & $\beta$ \\
\hline 50 & 2,52 & 88,49 \\
60 & 1,504 & 70,86 \\
80 & $5,800 \times 10^{-7}$ & 27,92 \\
\hline
\end{tabular}

A Figura 1, por sua vez, ilustra o comportamento dos parâmetros como uma função da temperatura do ar de secagem, variando entre 50 e $80^{\circ} \mathrm{C}$.

Como pode ser observado na Figura 1, os parâmetros foram apropriadamente ajustados à uma expressão do tipo logarítmica, como uma função da temperatura do ar de secagem. Os valores do coeficiente de determinação $\left(\mathrm{R}^{2}\right)$, superiores a 98\%, indicam que o comportamento dos parâmetros da Equação 6 foi bem representado pelo ajuste.
No que se refere ao ajuste do coeficiente convectivo de transferência de massa, estudos semelhantes ao presente foram conduzidos nos trabalhos de Mancini, Massarani e Biscaia Jr (2002), que estudaram a secagem de milho em camada espessa e leito deslizante; Martins, Mancini e Biscaia Jr (2002), que estudaram a cinética da secagem de feijão em camada delgada; e Elias, Barbosa e Mancini (2002), que estudaram a secagem de grão de bico em leito fixo.

Figura 1 - Ajuste dos parâmetros $\alpha$ e $\beta$.
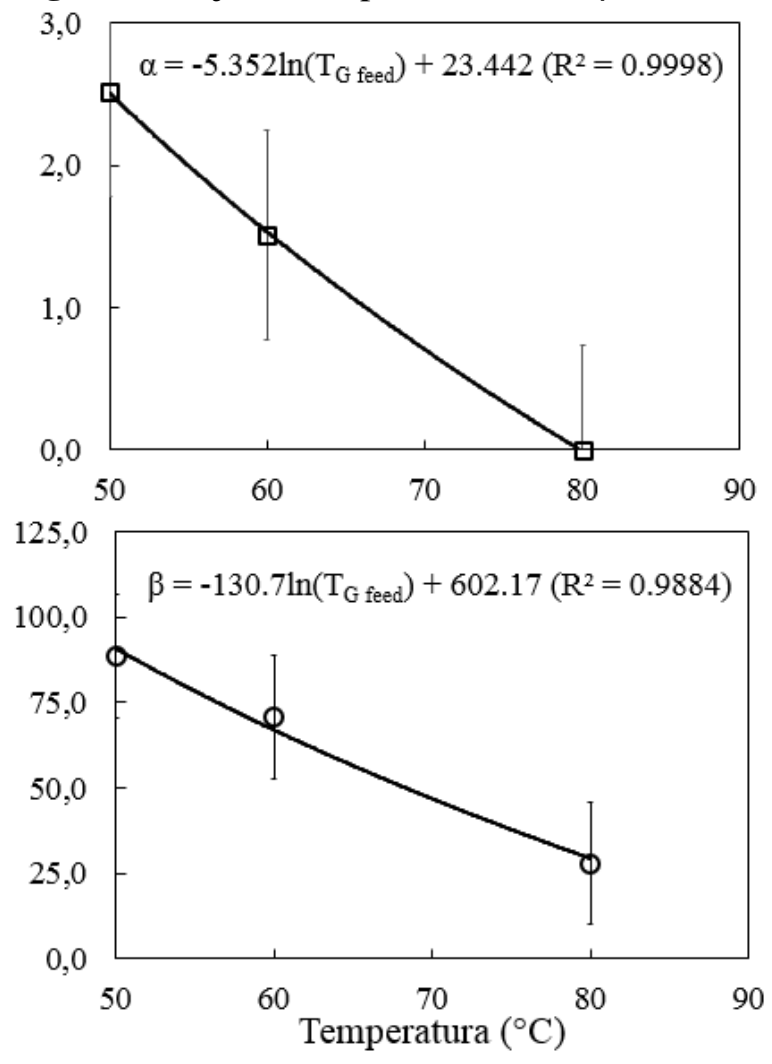

Nos trabalhos supracitados, os valores dos coeficientes $\alpha$ e $\beta$ foram calculados, resultando em comportamentos distintos. Mancini, Massarani e Biscaia Jr (2002) obtiveram relações entre os coeficientes e a temperatura do ar de secagem (em Kelvin) iguais a:

$\alpha=2,20+6,18 \times 10^{-3} \mathrm{~T}_{\mathrm{G}}$

$\beta=7,31+1,77 \times 10^{-2} \mathrm{~T}_{\mathrm{G}}$ 
Por sua vez, Martins, Mancini e Biscaia Jr (2002), chegaram aos valores apresentados na Tabela 3.

Tabela 3 - Parâmetros da Equação 6 ajustados por Martins, Mancini e Biscaia Jr (2002).

\begin{tabular}{ccc}
\hline Temperatura & $\alpha$ & $\beta$ \\
\hline $40,2^{\circ} \mathrm{C}$ & 0,145 & 0,847 \\
$45,2^{\circ} \mathrm{C}$ & 0,129 & 0,834 \\
$65,2^{\circ} \mathrm{C}$ & 0,073 & 0,789 \\
$70,0^{\circ} \mathrm{C}$ & 0,060 & 0,778 \\
\hline
\end{tabular}

Elias, Barbosa e Mancini (2002), estimaram os valores de $\alpha$ e $\beta$ conforme:

$\alpha=0,200+0,0020 \mathrm{~T}_{\mathrm{G}}$

$\beta=0,9991-0,0164 \mathrm{~T}_{\mathrm{G}}$

Dos resultados apresentados nos três trabalhos, observa-se que o coeficiente $\alpha$ apresentou relação de incremento com a elevação da temperatura do ar de secagem (MANCINI, MASSARANI e BISCAIA JR, 2002; ELIAS, BARBOSA e MANCINI, 2002) e de redução com o acréscimo da temperatura do ar de secagem (MARTINS, MANCINI e BISCAIA JR, 2002). Já o coeficiente $\beta$ sofreu acréscimo apenas no trabalho de Mancini, Massarani e Biscaia Jr (2002) e decréscimo nos estudos conduzidos por Martins, Mancini e Biscaia Jr (2002) e Elias, Barbosa e Mancini (2002), quando a temperatura do ar de secagem foi elevada.

No presente estudo, portanto, observouse relação semelhante àquela observada por Martins, Mancini e Biscaia Jr (2002), em que ambos os coeficientes foram reduzidos com o incremento de temperatura.

A Figura 2 ilustra o comportamento dos dados experimentais e os resultados obtidos a partir de simulações numéricas, para $\mathrm{o}$ processo de secagem a 50,60 e $80{ }^{\circ} \mathrm{C}$, a 1 $\mathrm{m} \mathrm{s}^{-1}$.

A influência da temperatura do ar de secagem pode ser observado, verifica-se que, mantendo constante a velocidade e aumentando a temperatura do ar, diferentes tempos de equilíbrio podem ser obtido. Quanto mais elevada for a temperatura, menor é o tempo necessário para alcançar o equilíbrio entre as sementes de abóbora e o ar de secagem.

Figura 2 - Evolução temporal da umidade das sementes de abóbora para diferentes temperaturas do ar de secagem.

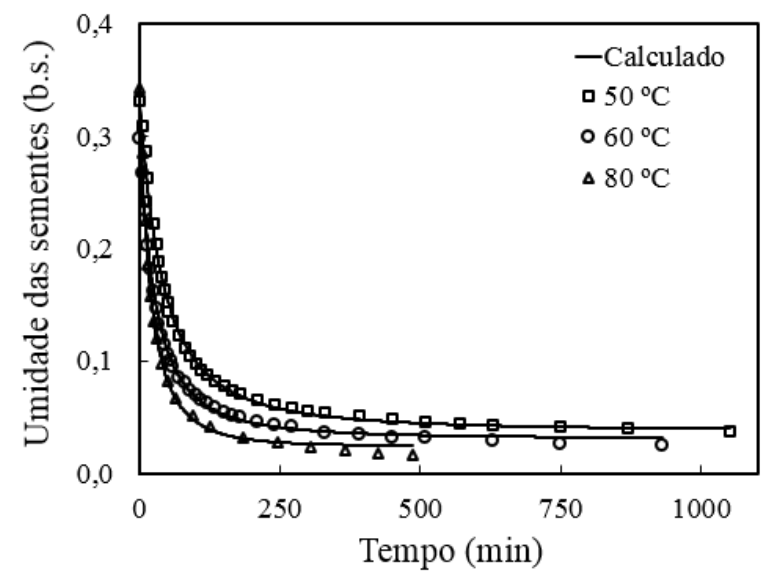

A Tabela 4 apresenta os resultados estatísticos da análise dos erros médios, obtidos a partir da comparação entre os dados experimentais de Diógenes et al. (2013) e os valores calculados para a umidade das sementes de abóbora. Por sua vez, a Tabela 5 exibe os valores calculados do coeficiente de correlação e do Critério de Seleção de Akaike, para cada uma das temperaturas estudadas no presente trabalho.

Tabela 4 - Análise estatística dos erros

\begin{tabular}{lll}
\hline Temperatura & Erro médio & Erro máximo \\
\hline $50{ }^{\circ} \mathrm{C}$ & $7,37 \%$ & $12,52 \%$ \\
$60{ }^{\circ} \mathrm{C}$ & $8,11 \%$ & $15,04 \%$ \\
$80{ }^{\circ} \mathrm{C}$ & $3,20 \%$ & $12,14 \%$ \\
\hline
\end{tabular}

Tabela 5 - Análise estatística de $\mathrm{R}^{2}$ e AIC

\begin{tabular}{lll}
\hline Temperatura & $\mathrm{R}^{2}$ & AIC \\
\hline $50^{\circ} \mathrm{C}$ & 0,9973 & $-318,20$ \\
$60^{\circ} \mathrm{C}$ & 0,9964 & $-296,90$ \\
$80^{\circ} \mathrm{C}$ & 0,9975 & $-233,50$ \\
\hline
\end{tabular}


Da análise das Tabela 4, foi possível verificar que o erro médio global entre os teores de umidade experimentais e calculados foi de $6,23 \%$, sendo os maiores erros médio e máximo, respectivamente 8,11 e $15,04 \%$, foram calculados para a temperatura do ar de secagem de $60^{\circ} \mathrm{C}$.

Em relação ao coeficiente de determinação, na Tabela 5 verificou-se que para todas as condições simuladas, obtiveramse valores superiores a 99\%. De acordo com o Critério de Seleção de Akaike, que permite indicar que o modelo mais adequado ao ajuste é aquele cujo valor de AIC for menor (FLORIANO et al. 2006), o modelo desenvolvido descreveu mais adequadamente o comportamento da cinética de secagem conduzida a $1 \mathrm{~m} \mathrm{~s}^{-1}$ e $50{ }^{\circ} \mathrm{C}$.

\section{CONCLUSÕES}

Foi estudado o processo de secagem convectiva de sementes de abóbora, por meio de um modelo fenomenológico, constituído de duas equações diferenciais ordinárias. $\mathrm{O}$ coeficiente de transferência convectiva de massa foi avaliado como uma função da umidade das sementes e da temperatura do ar de secagem.

Ambos os parâmetros que compõem a equação linear, empregada para cálculo do coeficiente de transferência de massa, foram reduzidos com o incremento de temperatura do ar de secagem.

Os resultados estatísticos indicaram que o modelo descreveu mais de $99 \%$ dos dados experimentais da literatura, apresentando um o erro médio global entre os teores de umidade experimentais e calculados iguala 6,23\%.

Dessa forma, pode-se concluir que as considerações iniciais, o modelo proposto, o ajuste linear do coeficiente convectivo de transferência de massa, e o método numérico empregados no estudo da secagem convectiva de sementes de abóbora foram adequados, resultando em conformidade com os dados experimentais, nas mesmas condições modeladas e simuladas no presente estudo.

\section{NOMENCLATURA}

\begin{tabular}{|c|c|}
\hline & Atividade da água (-) \\
\hline o.s. & Base seca $(\mathrm{kg} / \mathrm{kg})$ \\
\hline$c p_{S}$ & $\begin{array}{l}\text { Calor específico do grão } \\
\left(\mathrm{kJ} \mathrm{kg}^{-1 \circ} \mathrm{C}^{-1}\right)\end{array}$ \\
\hline & Erro médio $(\%)$ \\
\hline FOB & Função objetivo \\
\hline$h_{c}$ & $\begin{array}{l}\text { Coeficiente volumétrico de } \\
\text { transferência de calor }\left(\mathrm{W} \mathrm{m}^{-3}{ }^{\circ} \mathrm{C}^{-1}\right)\end{array}$ \\
\hline $\mathrm{H}_{\mathrm{S}}$ & Entalpia das sementes $\left(\mathrm{kJ} \mathrm{kg}^{-1}\right)$ \\
\hline K & $\begin{array}{l}\text { Número de parâmetros do modelo a } \\
\text { ser analisado }\end{array}$ \\
\hline $\mathrm{k}_{\mathrm{F}}$ & $\begin{array}{l}\text { Coeficiente convectivo de } \\
\text { transferência de massa } \\
\left(\mathrm{kg} \mathrm{m}^{-2} \mathrm{~min}^{-1}\right)\end{array}$ \\
\hline nexp & Número de dados experimentais \\
\hline SQ & Soma de quadrados dos desvios \\
\hline & Tem \\
\hline $\mathrm{T}_{\mathrm{G}}$ & Temperatura do ar de secagem $\left({ }^{\circ} \mathrm{C}\right)$ \\
\hline $\mathrm{T}_{\mathrm{S}}$ & Temperatura das sementes $\left({ }^{\circ} \mathrm{C}\right)$ \\
\hline $\mathrm{T}_{\mathrm{S}_{0}}$ & Temperatura inicial do grão $\left({ }^{\circ} \mathrm{C}\right)$ \\
\hline$X$ & Umidade das sementes (b.s.), \\
\hline$X_{0}$ & Umidade inicial (b.s.) \\
\hline$\overline{\mathrm{X}_{\mathrm{CAL}}}$ & $\begin{array}{l}\text { Umidade média do calculada do } \\
\text { leito pela resolução do modelo (b.s. }\end{array}$ \\
\hline $\mathrm{X}_{\mathrm{E}}$ & Umidade de equilíbrio (b.s.) \\
\hline$\overline{\mathrm{X}_{\mathrm{EXP}}}$ & $\begin{array}{l}\text { Umidade média experimental do } \\
\text { leito (b.s.) }\end{array}$ \\
\hline Y & Umidade do ar de secagem (b.s.) \\
\hline $\mathrm{Y}^{*}$ & $\begin{array}{l}\text { Umidade de equilíbrio do ar de } \\
\text { secagem (d.b.) }\end{array}$ \\
\hline$\alpha$ & Parâmetro ajustável da Equação 6 \\
\hline$\beta$ & Parâmetro ajustável da Equação 6 \\
\hline$\varepsilon$ & Porosidade do leito (-) \\
\hline$\Phi$ & Esfericidade média das sementes (-) \\
\hline$\lambda$ & $\begin{array}{l}\text { Calor de vaporização da água pura } \\
\left(\mathrm{kJ} \mathrm{kg}^{-1}\right)\end{array}$ \\
\hline & Densidade das sementes $\left(\mathrm{kg} \mathrm{m}^{-3}\right)$ \\
\hline
\end{tabular}

\section{REFERÊNCIAS}




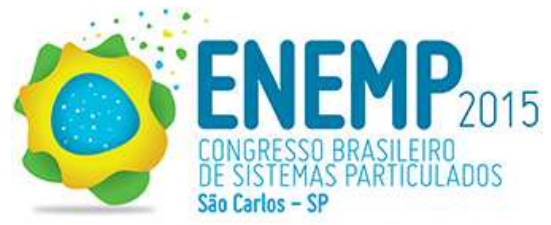

AKAIKE, H. Information theory and an extension of the maximum likelihood principle. In: International Symposium on Information Theory, 2.., 1973, Budapest. Anais... Budapest: Symposium on Information Theory, p. 267-281, 1973.

BELMIRO, T. M. C.; QUEIROZ, A. J. M.; FIGUEIRÊDO, R. M. F.; FERNANDES, T. K. S.; BEZERRA, M. C. T. Alterações químicas e físico-químicas em grãos de abóbora durante o armazenamento. Revista Brasileira de Engenharia Agrícola e Ambiental, v. 14, n. 9, p. 1000-1007, 2010.

BORÉM, F. M. Pós colheita do café. Lavras: UFLA, 2008.

ÇAKMAK, G.; YILDIZ, C. Design of a new solar dryer system with swirling flow for drying seeded grape. International Communications in Heat and Mass Transfer, v. 36, p. 984-990, 2009.

CARAMEZ, S. M. B.; STEFANI, M.; MEDEIROS, J. D.; VIEIRA, M. A.; BRÜSKE, G. R.; DE FRANCISCO, A.; AMANTE, E. R. Softening of pumpkin seeds (Cucurbita Moschata) by alcaline maceration. Journal of Food Process Engineering, v. 31, n. 4, p. 431-442, 2008.

COELHO, A. M.; ANDRADE, L. A. B.; FINCH, E.O. Secagem e armazenamento de grãos e sementes. Informativo Agropecuário, v.5, 1979.

CORRÊA, P. C.; MARTINS, D. S. R.; MELO, E. C. Umigrãos: programa para o cálculo do teor de umidade de equilíbrio para os principais produtos agrícolas. Viçosa: Centreinar - UFV, 1995.

DALPASQUALE, V. A.; SPERANDIO, D.; SILVA, L.H.M. Fixed-bed drying simulation with constant enthalpy, using the improved
Michigan State University model. Acta Scientiarum Technology, v. 34, p. 137-140, 2012.

DEL-VECHIO, G.; CORRÊA, A. D.; ABREU, C. M. P.; SANTOS, C. D. Efeito do tratamento térmico em sementes de abóboras (Cucurbita spp.) sobre os níveis de fatores antinutricionais e/ou tóxicos. Ciência e Agrotecnologia, v. 29, n. 2, p. 369-376, 2005.

DIÓGENES, A. M. G.; QUEIROZ, A. J. M.; FIGUEIRÊDO, R. M. F.; SANTOS, D. C. Cinética de secagem de grãos de abóbora. Revista Caatinga, v. 26, n. 1, p. 71-80, 2013.

ELIAS, R. N.; BARBOSA, A. L. S.; MANCINI, M. C. Secagem de grão de bico em leito fixo. Revista Universidade Rural, v. 21, n. 1, p. 113-119, 2002.

ESMAIILI, M.; REZAZADEH, G.; SOTUDEH-GHAREBAGH, R.; TAHMASEBI, A. Modeling of the Seedless Grape Drying Process using the Generalized Differential Quadrature Method. Chemical Engineering Technology, v. 30, p. 168-175, 2007.

ESUOSO, K.; LUTZ, H.; KUTUBUDDIN, M.; BAYER, E. Chemical composition and potential of some underutilized tropical biomass. I: fluted pumpkin (Telfairia occidentalis). Food Chemistry, v. 61, n. 4, p. 487-92, 1998.

FLORIANO, E. P.; MÜLLER, I.; FINGER, C. A. G.; SCHEIDER, P. R. Fitting and selecting traditional models for tree's height time series data. Ciência Florestal, v.16, n. 2, p. 177-199, 2006.

KOCABIYIK, H.; KAYISOGLU, B.; TEZER, D. Effect of Moisture Content on Thermal Properties of Pumpkin Seed. International 
Journal of Food Properties, v. 12, n. 2, p. 277-285, 2009.

MANCINI, M. C.; MASSARANI, G.; BISCAIA JR, E. C. In: Congresso Brasileiro de Sistemas Particulados, 21., Ouro Preto. Anais...Ouro Preto: ENEMP, 1993.

MANCINI, M. C.; MASSARANI, G.; BISCAIA JR, E. C. Transferência de massa na secagem de milho em secadores de camada espessa em leito fixo e deslizante. Revista Universidade Rural, v. 21, n. 1, p. 121-129, 2002

MARTINS, M. G.; MANCINI, M. C.; BISCAIA JR, E. C. Secagem de grão de bico em leito fixo. Revista Universidade Rural, v. 21, n. 1, p. 83-88, 2002.

MENDES, R. H.; DI PIETRO, P. F. Avaliação da composição química da semente de abóbora (Cucurbita pepo) e do efeito do seu consumo sobre o dano oxidativo hepático de ratos (Rattus novergicus). In: Reunião Anual da SBPC, 58., 2006, Florianópolis. Anais eletrônicos... São Paulo: SBPC/UFSC, 2006.

SACILIK, K. Effect of drying methods on thin-layer drying characteristics of hull-less seed pumpkin (Cucurbita pepo L.). Journal of Food Engineering, v. 79, p. 23-30, 2007.

SANT'ANNA, L. C.; BOAVENTURA, B. C. B.; KUNRADI, F. G.; TRAMONTE, V. L.;

SINGH, R. K., VISHAL, M.K., VISHWAKARMA, R.K. Moisture Dependent Physical Properties of Anise Seeds. International Journal of Food Processing Technology, v. 2, p. 39-45, 2015.

TEIXEIRA, L. P.; ANDRADE, E. T.; FIGUEIRA, V. G. Determinação do equilíbrio higroscópico dos grãos de abóbora (Cucurbita moschata). In: Congresso Brasileiro de
Engenharia Agrícola - CONBEA, 18., 2014, Campo Grande. Anais... Campo Grande: Associação Brasileira de Engenharia Agrícola, 2014.

TREYBAL, R. E. Mass-transfer operations, New York: McGraw Hill, 1980.

\section{AGRADECIMENTOS}

Os autores agradecem a Coordenação de Aperfeiçoamento de Pessoal de Nível Superior (CAPES) pela concessão da bolsa de doutorado à aluna Gracielle Johann. 